\title{
Correction to: Community Well-Being in Neighbourhoods: Achieving Community and Open-Minded Space through Engagement in Neighbourhoods
}

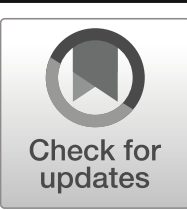

\section{Meg Holden ${ }^{1}$}

Published online: 20 May 2019

(C) Springer Nature Switzerland AG 2019

\section{Correction to: International Journal of Community Well-Being https://doi.org/10.1007/s42413-018-0005-1}

This work was supported by the Ministry of Education of the Republic of Korea and the National Research Foundation of Korea (NRF-2016S1A3A2924563) and by the Social Sciences and Humanities Research Council of Canada, through Insight Grant 435-2014-0465. The author also gratefully acknowledges the feedback received on an earlier draft from other participants at the 4th International Forum on Community Wellbeing in Brisbane, Australia, and the research assistance of Ana Molina.

Publisher's Note Springer Nature remains neutral with regard to jurisdictional claims in published maps and institutional affiliations.

The online version of the original article can be found at https://doi.org/10.1007/s42413-018-0005-1

Meg Holden

mholden@sfu.ca

1 Urban Studies and Geography, Simon Fraser University, 2nd Floor, 515 W. Hastings St, Vancouver, BC V6B 5K3, Canada 